results are hardly surprising. It is much cheaper to treat an acute curable illness such as malaria than to try to rehabilitate a patient with advanced rheumatic heart disease. The general ward and the intensive care unit may seem expensive, but not in terms of medicine in the Western world. The average cost of treating malaria in a New York hospital ${ }^{2}$ has been calculated at $\$ 1745$, and the bill for one particular patient $(\$ 7702)$ would cover the running costs of the adult observation ward for five weeks.

It is often thought that most tropical illness could be either prevented or treated in dispensaries at little cost. There is much sense in this, but careful inspection of the diseases causing admission suggests that available and economic methods of prevention will have little impact on these admissions. The problem of treating curable diseases at dispensaries is largely one of diagnosis. Certainly many illnesses are accurately diagnosed and treated at dispensaries and health centres, but diagnosis is not always simple. Many of these curable patients arrive at the hospital after two or more visits to dispensaries and hospitals. Clinical diagnosis of even malaria may be wildly inaccurate. ${ }^{3}$ Treatment at any level without a precise diagnosis is likely to be money wasted.

If anything can be done to lower the cost per effective admission it must be in the group 3 and group 4 patients. Unfortunately, it is difficult to see what can be done. Group 4 patients must be admitted, at least initially, to allow a certain diagnosis to be made. Often by the time the incurable nature of the illness has been established patients are too ill to go home. Although help for a group 3 patient is often only temporary, there seems no obvious way (apart from withdrawing medical care) of reducing the expense of managing, for example, diabetic coma or haematemesis from schistosomal portal hypertension.

Finally, the reference hospitals are also teaching hospitals. They teach not only doctors, both undergraduate and postgraduate, but also nurses, physiotherapists, and paramedical staff. Their expense might well be justified by this aspect of their function alone.

We are most grateful to Mr L K Ndungu, senior hospital secretary, for help with the costing; to Mrs J D Ndegwa, medical records officer, and Dr I Sadiqali for their help in collecting data; and to $\mathrm{Dr}$ $\mathrm{H}$ de Glanville, of the African Medical Research Foundation, for much help in preparing the manuscript.

\section{References}

${ }^{1}$ British Medical fournal, 1977, 1, 1117.

2 Kean, B H, and Reilly, P C, American fournal of Medicine, 1976, 61, 159

${ }^{3}$ Rees, P H, et al, East African Medical fournal, 1971, 48, 51.

(Accepted 2 March 1978)

\title{
Bone-marrow relapse in acute lymphoblastic leukaemia in childhood
}

\author{
M A CORNBLEET, JUDITH M CHESSELLS
}

British Medical fournal, 1978, 2, 104-106

\section{Summary and conclusions}

The outcome after bone-marrow relapse was assessed in 53 children with acute lymphoblastic leukaemia (ALL). Twenty-five out of 37 children $(67 \%)$ whose first remission ended in relapse during treatment (group A) achieved a second remission, as did 15 out of $16(94 \%)$ who relapsed after treatment had been stopped (group B). Nevertheless, the median duration of second remission was only 12 weeks in group $A$ and 35 weeks in group $B$. The median survival from time of relapse was 32 weeks in group $A$ and 75 weeks in group $B$.

It is concluded that marrow relapse is equally serious whether it occurs during treatment or after treatment has been stopped, and that most children with ALL have a single chance of cure at the time of diagnosis.

Department of Haematology, The Hospital for Sick Children, London WC1N 3JH

M A CORNBLEET, BSC, MRCP, leukaemia research fellow

JUDITH M CHESSELLS, MD, MRCP, consultant clinical haematologist

\section{Introduction}

Despite well-publicised advances in managing acute lymphoblastic leukaemia (ALL) in childhood, treatment is ultimately unsuccessful in at least half of all patients. In children with ALL treated with combination chemotherapy and central nervous system (CNS) "prophylaxis" the bone marrow is the most common site of first relapse. We report our experience in managing children with ALL whose first remission ended in haematological relapse, and compare the outcome after relapse during treatment with that following relapse after completing two or three years' chemotherapy.

\section{Patients and methods}

Between 1972 and 1977 bone-marrow relapse ended the first complete remission in 53 children treated at the Hospital for Sick Children (see table). Thirty-seven of these children (group A) had relapsed during treatment and 16 (group B) after treatment had been stopped after two or three years' continuous complete remission. One of the children in group A had a simultaneous marrow and CNS relapse and two children in group $\mathrm{B}$ a simultaneous marrow and testicular relapse.

All children had been treated according to protocols designed by the Medical Research Council Working Party on Leukaemia in Childhood or being piloted for them. All the protocols included prednisolone and vincristine during induction of remission and CNS 
Number of children with acute lymphoblastic leukaemia in whom first remission ended in relapse during treatment (group $A$ ) or after treatment had been stopped (group $B$ ), and number achieving second remission

\begin{tabular}{|c|c|c|c|c|c|}
\hline & $\begin{array}{c}\text { No of } \\
\text { patients }\end{array}$ & $\begin{array}{l}\text { No of } \\
\text { males }\end{array}$ & $\begin{array}{c}\text { Median } \\
\text { duration } \\
\text { of first } \\
\text { remission } \\
\text { (wks) } \\
\text { (range) }\end{array}$ & $\begin{array}{l}\text { No }(\%) \\
\text { achieving } \\
\text { second } \\
\text { remission }\end{array}$ & $\begin{array}{c}\text { Median } \\
\text { duration } \\
\text { of second } \\
\text { remission } \\
\text { (wks) } \\
\text { (range) }\end{array}$ \\
\hline Group A: & 37 & 23 & $48(14-123)$ & $25(67)$ & $12(3-45+*)$ \\
\hline $\begin{array}{l}\text { "Grognosis } † \\
\text { "Good" }\end{array}$ & 16 & 11 & $46(14-87)$ & 10 & $7(3-13)$ \\
\hline $\begin{array}{l}\text { prognosis } \\
\text { Group B }\end{array}$ & $\begin{array}{l}21 \\
16\end{array}$ & $\begin{array}{l}12 \\
10\end{array}$ & $\left|\begin{array}{c}56(20-123) \\
172(116-204)\end{array}\right|$ & $\begin{array}{l}15 \\
15(97)\end{array}$ & $\begin{array}{l}14(3-45+*) \\
35(6-84+\ddagger)\end{array}$ \\
\hline
\end{tabular}

* Study terminated at 45 weeks.

Patients aged over 14 at diagnosis or presenting with white cell count $>20 \times 10^{\circ} /$ $\left(>20000 / \mathrm{mm}^{3}\right)$, or both

¥ Study terminated at 84 weeks.

prophylaxis, with cranial irradiation and intrathecal methotrexate, or spinal irradiation and continuing multiple-agent chemotherapy (which included methotrexate and mercaptopurine and pulses of prednisolone and vincristine), or both. Children who remained in complete remission stopped treatment after two or three years.

Haematological relapse was diagnosed if bone-marrow examination showed that the marrow contained over $5 \%$ abnormal blast cells. In practice, the marrow usually contained well over this proportion, since if the appearances were equivocal it was our policy to continue treatment according to schedule and to repeat the examination after four to six weeks. Remission was confirmed by re-examination of the marrow, and remission duration was calculated from this date. Duration of survival was calculated from the date of first relapse.

Patients who relapsed during treatment (group A) were treated with various drug combinations. No further CNS prophylaxis was given, but the child with concurrent meningeal relapse was treated with regular intrathecal methotrexate. ${ }^{1}$ In children who relapsed after treatment (group B) induction of remission was attempted with prednisolone and vincristine, and consolidation chemotherapy was given. The patients received no further cranial irradiation, but a course of five intrathecal methotrexate injections was given as CNS prophylaxis. Continuing treatment was not the same in all cases, but children received either the UKALL II regimen ${ }^{2}$ or another combination of mercaptopurine and methotrexate. The two boys with concurrent testicular disease received 1500 rads irradiation to both testes.

\section{Results}

A second remission was achieved in 25 of the 37 children $(67 \%)$ who relapsed during treatment. Three drug combinations have been most consistently used since 1972 in our attempts to achieve a second remission: prednisolone and vincristine was successful in three out of eight children; prednisolone, vincristine, daunorubicin, and cytosine arabinoside (cytarabine) in five out of 11 children; and recently prednisolone, vincristine, L-asparaginase (colaspase), and paired injections of daunorubicin given on two consecutive days achieved remission in 10 out of 11 children. Nevertheless, the median duration of remission in the 25 children in group A (fig 1) was only 12 weeks, and the median survival for the whole group of 37 children (fig 2) was 32 weeks from the time of first relapse. In only two children was the duration of second remission almost as long as the first remission; one of these two died from a probable viral infection associated with wasting and a rash during the second remission. Despite the absence of further CNS prophylaxis, the second remission ended in CNS relapse in only two children; in the others (including the boy whose first relapse occurred in CNS and marrow simultaneously) the second relapse was haematological. Survival in the 12 children who did not achieve remission ranged from four to 54 weeks (median duration 15 weeks).

Fifteen of the 16 children $(94 \%)$ who relapsed after stopping treatment (group B) achieved a second remission. One girl died from pneumonia during the first week of reinduction. Prednisolone and vincristine were successful in 10 out of 16 children; in five others additional treatment was needed to achieve remission. At the time of the study the median duration of complete remission in this group (fig 1) was 35 weeks; one child had a CNS relapse, and one who had achieved complete remission died from septicaemia complicating portal cirrhosis which was ascribed to methotrexate toxicity. The median survival in the whole group (fig 2) was 72 weeks from the date of first relapse. Three of the eight children who relapsed within six months of stopping treatment and four of the eight who relapsed later remained in a second complete remission.

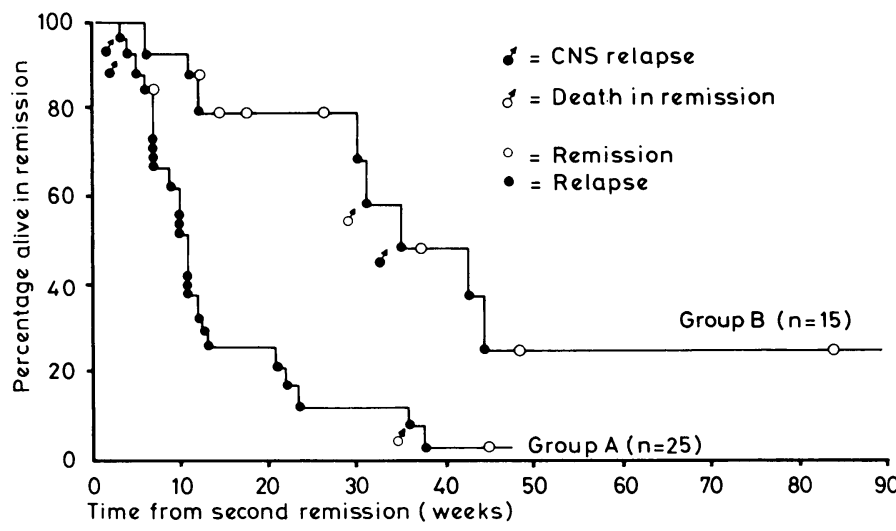

FIG 1-Duration of second complete remission from acute lymphoblastic leukaemia in the 40 children in the two patient groups who achieved a second complete remission.

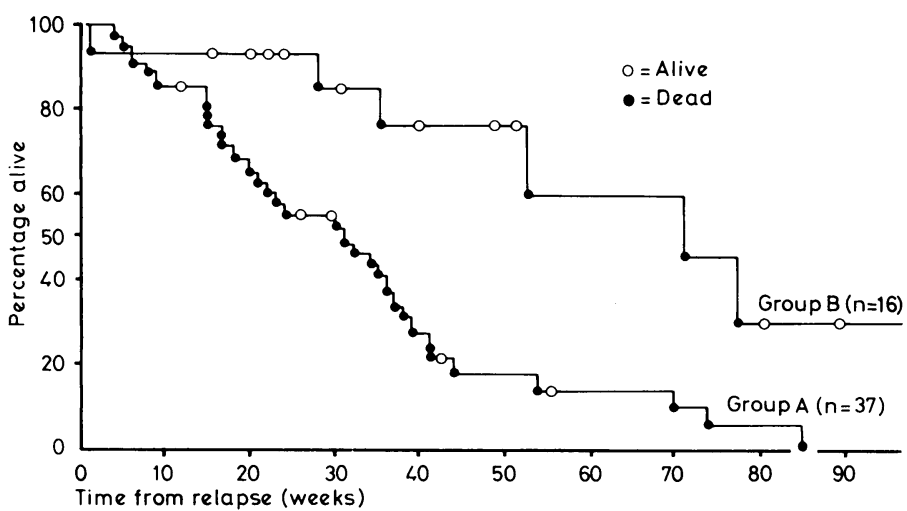

FIG 2-Duration of survival from time of first relapse in all 53 children with acute lymphoblastic leukaemia.

\section{Discussion}

These results emphasise the poor prognosis of children with ALL who have a bone-marrow relapse during treatment. Eighty per cent of these children died within one year of relapse. A second remission may be induced in most patients, but continued treatment remains the major problem, since the leukaemic cells are resistant to most previously used drugs. Our patients who relapsed after stopping treatment did better in the short term, but our results so far suggest that few of them will achieve long-term second remissions. Although the optimum duration of treatment for ALL remains in doubt, and may vary with treatment schedule and perhaps with sex, there are no grounds for thinking that prolonging treatment would decrease the subsequent relapse rate. In the Medical Research Council's UKALL II trial ${ }^{3}$ three years' treatment was not superior to two years'. We and others ${ }^{4}$ have found that most relapses occur within the first year of stopping treatment. These results are similar to those of the Memphis group, who concluded that marrow relapse is equally serious whether it occurs during or after treatment. ${ }^{\mathrm{E}}$

We find that prolonged second haematological remissions occur only in patients who received inadequate treatment from the time of first remission or who relapsed during an unmaintained remission after treatment according to the Concord protocol $^{6}$ or similar short, intensive regimens. Six out of 26 children who received such treatment at the Hospital for Sick Children achieved prolonged second marrow remissions lasting from three years to over eight years. Most reports of prolonged second haematological remission refer to children in one of these two categories. ${ }^{78}$ 
Clearly most children with ALL have a single chance of cure at the time of diagnosis, and no effort must be spared to ensure optimum treatment from the start to prevent relapse and not merely to postpone it. More-aggressive conventional chemotherapy will probably not substantially improve the outcome in patients who have already had a marrow relapse during treatment. It is in such patients that new therapeutic approaches such as bone-marrow transplantation ${ }^{9}$ are justifiable.

Meanwhile, in children who have a marrow relapse during treatment the benefits of achieving a second remission lasting a median of three months should perhaps be weighed against the cost to the child and his family in terms of discomfort, hospital attendance, and admissions. In these children above all others the major consideration should be the quality of life.

\section{References}

${ }^{1}$ Gribbin, M, Hardisty, R M, and Chessells, J M, Archives of Disease in Childhood, 1977, 52, 673.

2 Medical Research Council's Working Party on Leukaemia in Childhood, British fournal of Haematology, 1976, 33, 179.

${ }^{3}$ Medical Research Council's Working Party on Leukaemia in Childhood, in preparation.

${ }^{4}$ Aur, R J A, et al, New England fournal of Medicine, 1974, 291, 1230.

${ }^{5}$ Rivera, G, et al, Cancer, 1976, 37, 1679.

${ }^{6}$ Medical Research Council's Working Party on Leukaemia in Childhood, British Medical fournal, 1971, 4, 189.

${ }^{7}$ Aur, R J A, et al, Cancer, 1972, 30, 334.

${ }^{8}$ Leventhal, B G, et al, Cancer, 1975, 35, 1136

9 Thomas, E D, et al, Blood, 1977, 49, 511.

\section{Prevention of $\mathrm{Rh}$ haemolytic disease}

\section{A D TOVEY, JANE MURRAY, BERYLL J STEVENSON, J M TAVERNER}

British Medical fournal, 1978, 2, 106-108

\section{Summary and conclusions}

Between 1970 and 1976 in the Yorkshire region the incidence of $R h$ antibodies in $R h$-negative pregnant women fell by $70 \%$. This decrease occurred in both old (long-standing) and new (first-affected) cases, which emphasised that the reduction in numbers was as much due to fewer pregnancies among Rh-negative mothers as to administration of anti-D immunoglobulin. Nevertheless, the incidence has begun to level out. The continued incidence of first-affected cases is caused by three main factors: failure of administration of anti-D immunoglobulin after normal deliveries and abortions; a steady incidence of antibodies in primigravidae; and cases in which administration of anti-D immunoglobulin had failed to protect.

Administering anti-D antenatally might reduce the incidence of new cases among primigravidae who are sensitised before anti-D is normally given. Even without routine antenatal administration of anti-D, the incidence of severely affected $\mathrm{Rh}$ babies in the Yorkshire region could be reduced to one or two isolated cases a year in a population of three to four million by administering anti-D after all $\mathrm{Rh}$-negative deliveries and after every abortion.

\section{Introduction}

During the past few years there has been a dramatic fall in the incidence of $\mathrm{Rh}$ haemolytic disease. ${ }^{2}{ }^{2}$ This is due to two factors, firstly the appreciable fall in the number of Rh-negative women having babies, particularly if they had developed $\mathrm{Rh}$ antibodies previously; and secondly the routine administration of anti-D

Regional Transfusion Centre, Leeds LS15 7TW

L A D TOVEY, MD, FRCPATH, director

JANE MURRAY, BSC, MB, clinical assistant

BERYLL J STEVENSON, $\mathrm{MB}$, CHB, clinical assistant

J M TAVERNER, BSC, senior scientific officer immunoglobulin to Rh-negative women delivered of Rh-positive infants.

We describe the present position of $\mathrm{Rh}$ prophylaxis in an area of Yorkshire with a population of three and a half million and 44000 births a year, and discuss the measures available to reduce the incidence of $\mathrm{Rh}$ haemolytic disease still further.

\section{Present study}

OVERALL INCIDENCE OF BLOOD-GROUP ANTIBODIES 1970-6

From 1970 to 1976 the incidence of $\mathrm{Rh}$ antibodies in $\mathrm{Rh}$-negative women decreased by $70 \%$, the incidence of non- $\mathrm{Rh}$ antibodies in $\mathrm{Rh}$-negative women by $35 \%$, and that of antibodies in Rh-positive women by $19 \%$ (table I).

FACTORS INFLUENCING INCIDENCE OF RH ANTIBODIES IN RH-NEGATIVE WOMEN

If the fall in the incidence of $\mathrm{Rh}$ antibodies was primarily due to administration of anti-D immunoglobulin the incidence of "firstaffected" pregnancies (those in which antibodies were detected for the first time) should show a dramatic fall in incidence compared with "long-standing" cases. Our results show that this is not so (see table II). Between 1970 and 1976 the incidence of first-affected cases

TABLE I-Blood-group antibodies in pregnant women 1970-6

\begin{tabular}{|c|c|c|c|c|c|c|c|}
\hline & 1970 & 1971 & 1972 & 1973 & 1974 & 1975 & 1976 \\
\hline \multicolumn{8}{|c|}{ Rh-negative mothers } \\
\hline $\begin{array}{l}\text { No with anti-D, } C+D, \\
D+E, \text { and } C+D+E \\
\text { No with other antibodies }\end{array}$ & $\begin{array}{r}481 \\
26\end{array}$ & $\begin{array}{r}428 \\
24\end{array}$ & $\begin{array}{r}368 \\
28\end{array}$ & $\begin{array}{r}285 \\
34\end{array}$ & $\begin{array}{r}201 \\
24\end{array}$ & $\begin{array}{r}178 \\
17\end{array}$ & $\begin{array}{r}144 \\
17\end{array}$ \\
\hline \multicolumn{8}{|c|}{ Rh-positive mothers } \\
\hline No with antibodies & 111 & 110 & 111 & 100 & 117 & 79 & 90 \\
\hline
\end{tabular}

TABLE II-Numbers of women delivered with anti-D and ant $-D+C$ antibodies, and numbers of first-affected and long-standing cases, 1970-6*

\begin{tabular}{l|c|c|c|c|c|c}
\hline & 1970 & 1972 & 1973 & 1974 & 1975 & 1976 \\
\hline $\begin{array}{l}\text { Total No with anti-D and } \\
\text { anti-D +C }\end{array}$ & 469 & 346 & 278 & 195 & $\begin{array}{c}171 \dagger \\
65\end{array}$ & $\begin{array}{c}134 \\
60\end{array}$ \\
$\begin{array}{l}\text { No of first-affected cases } \\
\text { No of long-standing cases }\end{array}$ & 202 & 143 & 117 & 78 & 105 & 74 \\
\hline
\end{tabular}

*Data unavailable for 1971

tInsufficient information available on one patient to allow classification. 